\title{
Construction and Operation of Solar Powered Egg Incubator
}

\author{
Kelebaone Tsamaase, Kagiso Motshidisi, \\ Rapelang Kemoabe, Ishmael Zibani, Refilwe Moseki \\ Electrical Department, \\ University of Botswana \\ Gaborone, Botswana
}

\begin{abstract}
This paper deals with the solar powered egg incubator which has been constructed operated to show that it can work as expected. The incubator has been developed particularly for areas without any access to electricity grid but having potential for chicken farming. The carrying capacity of the constructed incubator is $\mathbf{4 0}$ eggs. However, large capacity incubators using the same principle of operation can be constructed as well. The incubator has proven to be working accordingly well because it was able to regulate internal temperatures and relative humidity to keep them within allowable temperature range and relative humidity range respectively. It was able to tilt the tray on their side at predetermined intervals. Further work will include demonstrating the effectiveness of the incubator by putting it in practice. Its efficiency will be determined as part of future work.
\end{abstract}

Keywords- Egg incubator, photovoltaic system, efficiency Introduction

\section{INTRODUCTION}

Chicken incubation is where by eggs are incubated and hatched with the use of technology or through man-made equipment. The normal hatching period is 21 days, same period taken by a hen when the natural hatching is taking place because egg incubation and chicks' raising is not part of the process. However, comparatively artificial incubation is more advantageous because when the hen has finished laying eggs, it does not take long before it lays again. For natural hatching, the hen generally spends 21 days from incubation to hatching. Requires another period from weeks to months to raise chicks and that is when thereafter it can start laying eggs again. Therefore, building and utilization of solar powered egg incubator improves the results of poultry of chicken farming and the overall living of the farmers and communities in general. There are areas which do not have access to the electricity grid. Examples can be places away from grid, place whose geographical positioning makes it very expensive to have grid extended to them. For these places, the viable option is use of off grid electricity supply in particular the solar PV system due to abundance of solar energy and its environmentally friendliness $[1,2]$. This paper is focusing on the building of an automated incubator powered from solar PV system [3]. The intention of the project is to further have an incubator which is built from locally acquired materials.

The rest of this paper is arranged as follows: Section II deals with energy source of the incubator, principle of operation of PV system, Section III operation of the system deals with main equipment used, Section IV deals with operation of proposed incubator system, Section V deals with system sizing, Section VI is on programme developed for loading into the micro controller, Section VII deals with equipment setup and the results, Section VIII is conclusion and future work

\section{ENERGY SOURCE OF THE SYSTEM}

The incubator was designed to be powered from solar energy system. Due to its nature of operation it was designed such that it useful in areas where there is no access to electricity grid. The system is designed such that it powers the motor directly if there is enough solar radiation. Alternatively where there is not enough solar energy input a battery is provided as an energy storage to provide power to the system [5]. A general schematic diagram of the PV system is show in Figure 1.

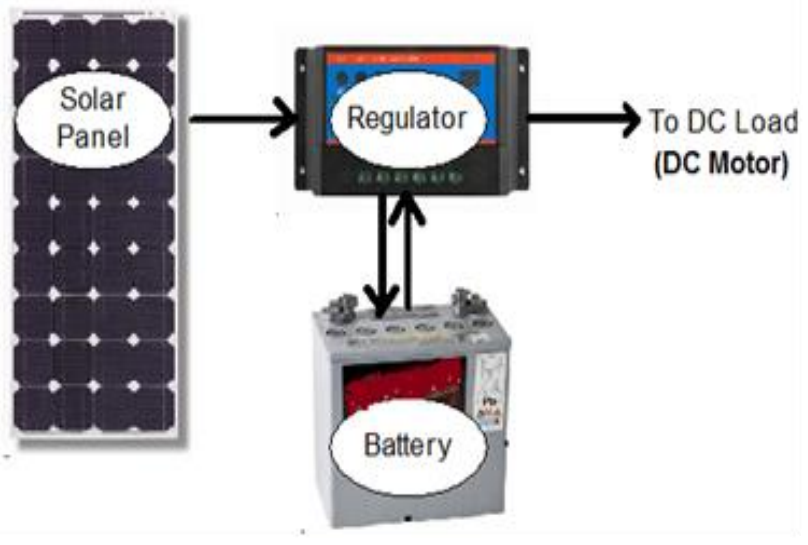

Figure 1 - schematic diagram of solar PV energy system [6]

\section{SYSTEM OPERATION}

There are three key parameters important for the incubation of eggs. These are relative humidity, temperature and egg turning defined in terms of angle of inclination of egg tray as it swings on either side of the axis. The schematic diagram showing a cross section of the incubator with features for the control of such parameters is show in figure 2. The bulbs are using to provide heating to raise temperature to the required range. The fan is used speed water evaporation from the water reservoir to increase humidity to the required level. The motor which is equipped with actuator mechanism is used to tilt egg tray at an angle of 45 degrees on either side of the axle at predetermined intervals. The incubator has electronic displays showing balance of days left before hatching. They also show the internal ambient temperature and relative humidity. The incubator components are powered from solar 
photovoltaic (PV) energy system. The system has the option of powering the circuits directly from the panel. Alternatively when there is not enough power from the panel the system is powered from a battery which is used as energy storage.

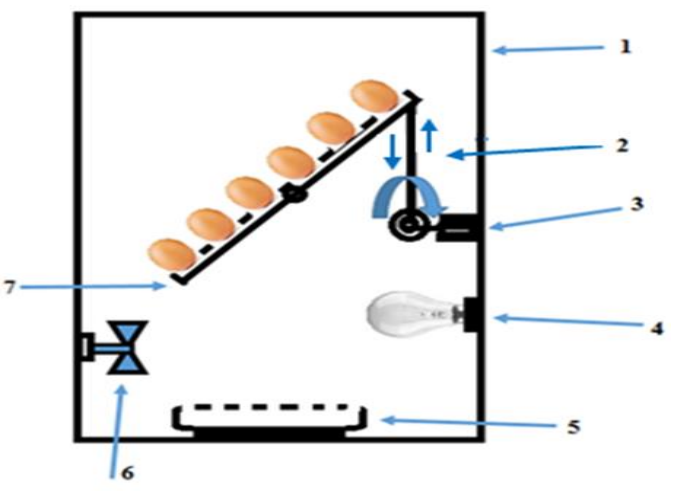

Figure 2 - Cross sectional view of the egg incubator

\section{EXPERIMENTAL SETUP}

The incubator was built as show in Figures 3 to 4. Figure 3 shows solar PV system connects whilst Figure 4 shows connections in Figure 4 show between the PV module, controller or regulator and the battery. The casing of cover was made from foam material. It was preferred because it was to susceptible to sudden change of temperatures and humidity and was easy and cheap to acquire. However, to make the casing durable, a thin hardboard was used to enclose the foam in between. Other components connection are as shown in Figure 4. Figure 5 shows the assembly and connection of dehumidifying fan which is used for regulating relative humidity in the incubator.

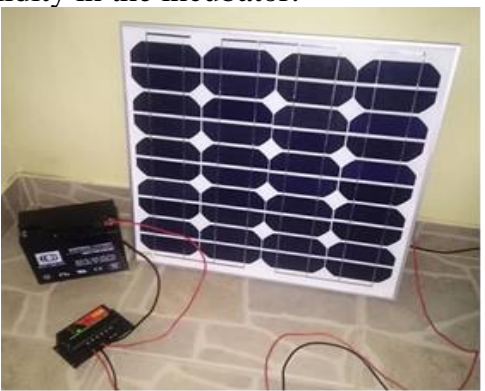

Figure 3: PV system components connections

PV system components connections

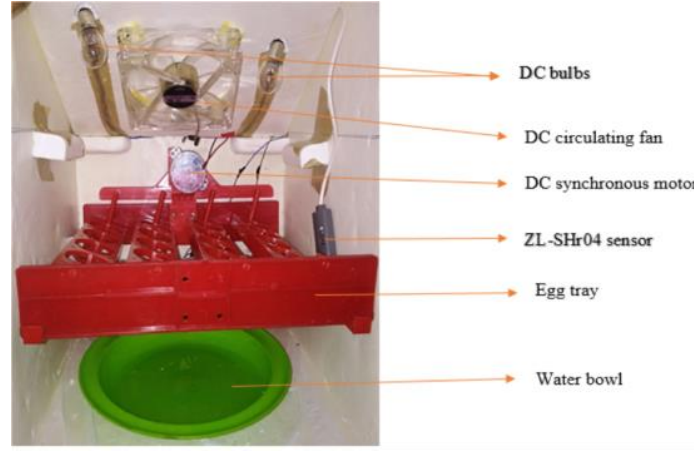

Figure 4: Experimental setup of the incubator

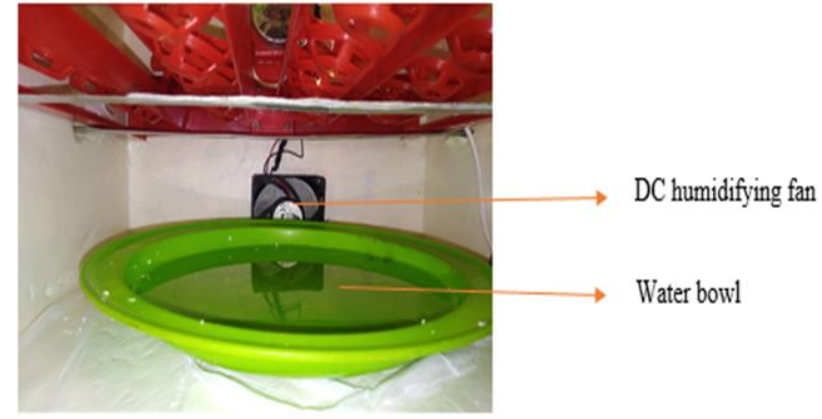

Figure 5 - shows DC humidifying fan and corresponding water reservoir

\section{RESULTS}

The result below were obtained when operating the incubator under different environmental or weather conditions. In Figure 6 the temperature fell below the normal operating temperature range. The temperature display unit reading shows 34.1 degrees celsius and a relative humidity reading of $24.4 \%$. This triggered, through temperature sensor, the bulbs to switch on as on the figure. When the temperature has reached the upper value of the temperature range, 39 degrees Celsius, the lights switched off as shown in Figure 7 where the temperature reading was 39.2 degrees and the lights went off. The relative humidity reading was $18.7 \%$. Regarding the turning of egg tray on either side of the axle, Figure 4 shows such turning. When it was supplied with power. Figure 8 shows the countdown of days (balance of days), starting with 21days, before hatching. The counter enables the user to make prior preparation form the small chicks before hatching. The parameters, temperature and relative humidity were monitored over a period of time and the results were recorded in Table 1. The results were also presented graphically as shown in Figures 9 and 10. Figure 6: Bulbs are $\mathrm{ON}$ when temperature is below $36.5^{\circ} \mathrm{C}$

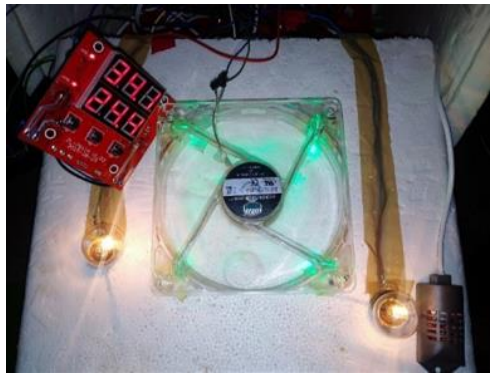

Figure 6 - The lights are on when temperature is below $36^{\circ} \mathrm{C}$

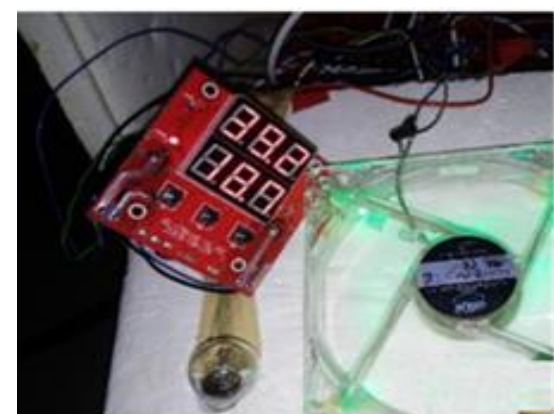

Figure 7: Bulbs are $\mathrm{OFF}$ when temperature increases beyond $39^{\circ} \mathrm{C}$ 


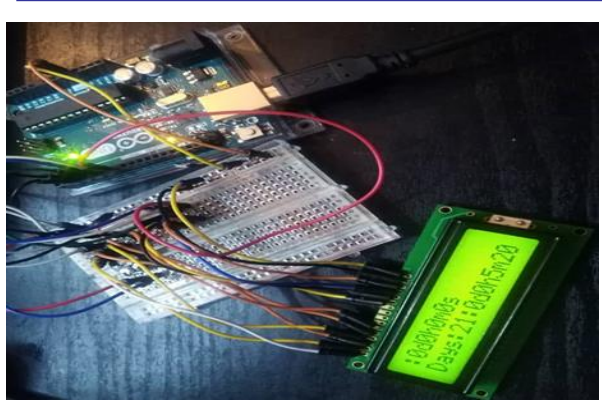

Figure 8 - Counter and display units for days left before hatching

Table 1: Ambient temperature readings (external and internal) and relative humidity (internal and external)

\begin{tabular}{|c|c|c|c|c|}
\hline \multicolumn{5}{|c|}{ April 25, 2019 } \\
\hline Time & Ambient Temperature ${ }^{\circ} \mathbf{C}$ ) & \multicolumn{2}{c|}{ Relative Humidity (\%) } \\
\hline Internal & External & Internal & External \\
\hline $9: 00 \mathrm{am}$ & 28.9 & 24.8 & 51.5 & 16.1 \\
\hline $9: 30 \mathrm{am}$ & 34.3 & 28.5 & 39.3 & 16.2 \\
\hline $10: 00 \mathrm{am}$ & 37.1 & 30.3 & 36.7 & 16.4 \\
\hline $10: 30 \mathrm{am}$ & 38.6 & 30.1 & 35.1 & 14.3 \\
\hline $11: 00 \mathrm{am}$ & 38 & 28.8 & 36.6 & 12.8 \\
\hline $11: 30 \mathrm{am}$ & 36.9 & 28.9 & 36.7 & 13 \\
\hline $12: 00 \mathrm{pm}$ & 38.4 & 28.9 & 31.8 & 12.3 \\
\hline $12: 30 \mathrm{pm}$ & 37.7 & 29.3 & 35.7 & 11.8 \\
\hline $1: 00 \mathrm{pm}$ & 37.9 & 29.2 & 48.6 & 13.1 \\
\hline $1: 30 \mathrm{pm}$ & 38.8 & 26.6 & 57.2 & 12.2 \\
\hline $2: 00 \mathrm{pm}$ & 39.2 & 27.2 & 58 & 11.1 \\
\hline $2: 30 \mathrm{pm}$ & 39.0 & 27.8 & 60.5 & 10.6 \\
\hline $3: 00 \mathrm{pm}$ & 38.8 & 29 & 56.3 & 15 \\
\hline $3: 30 \mathrm{pm}$ & 38.2 & 28.5 & 58.3 & 16.3 \\
\hline $4: 00 \mathrm{pm}$ & 36.9 & 29 & 61.7 & 24 \\
\hline $4: 30 \mathrm{pm}$ & 37.9 & 27.3 & 56.3 & 30.5 \\
\hline $5: 00 \mathrm{pm}$ & 38 & 26.9 & 54.1 & 31.6 \\
\hline $5: 30 \mathrm{pm}$ & 37.6 & 25.5 & 56.3 & 35.1 \\
\hline $6: 00 \mathrm{pm}$ & 37.2 & 25 & 56.4 & 37.4 \\
\hline & & & & \\
\hline
\end{tabular}

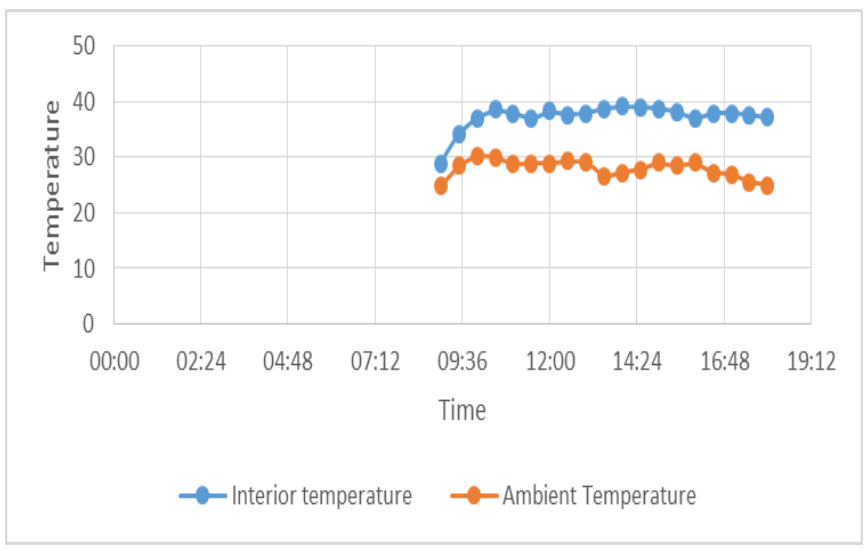

Figure 9 - Internal and external ambient temperatures

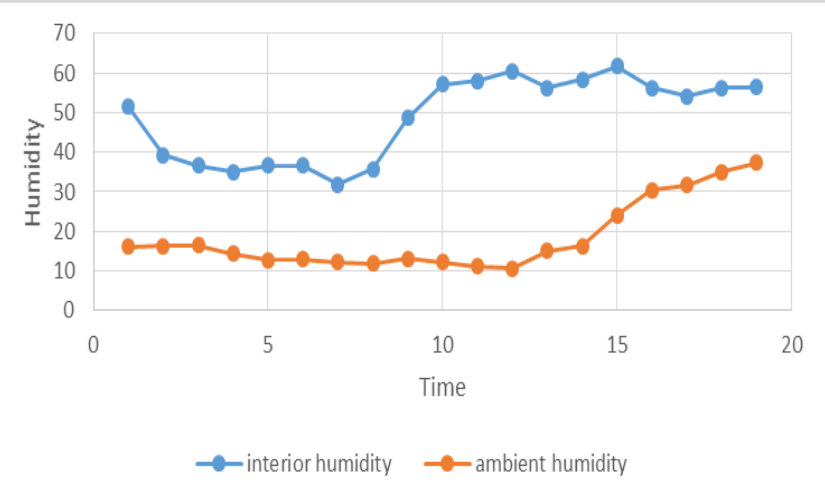

Figure 10 - Internal and external relative humidity

\section{ANALYSIS OF THE RESULTS}

The results as presented in Table 1 and in Figures 9 and 10 show that the design incubator successfully operated as expected. Figure 8 shows that though the external ambient temperature was in the range of around $30{ }^{\circ} \mathrm{C}$ the internal temperature readings were around $39{ }^{\circ} \mathrm{C}$. This internal temperature falls within design temperature range of 36 to 39 ${ }^{\circ} \mathrm{C}$. Regarding relative humidity, Figure 10 shows that the external relative humidity was low in the range of $10 \%$ to around $29 \%$. However, the internal relative humidity was increased from low values of around $30 \%$ to as high as $60 \%$. The final reading of around $60 \%$ also falls with the design range of the incubator. Same results are also presented in tabular form as shown in Table 1. The egg tray turning mechanism was operating accordingly as it managed to turn the try on either side not exceeding a preset value.

\section{CONCLUSION AND FUTURE WORK}

The results show that the incubator is working accordingly as expected. In was responding to temperature variations which fell outside set temperature range. The same was observed whereby it responded well to the relative humidity readings outside the set humidity range. The egg tray was also turning on either side to the axle or pivot with maximum tilt angle not exceeding 45 degrees. Also, the solar PV system provided enough power to operate the synchronous motor and also to provide power to other electronic gadgets in the system, and all the operating mechanism such as egg tray turning operated as expected. For further work the incubator packaging is to be improved and be tested under normal working environment with eggs inside.

\section{REFERENCES}

[1] M. O. North and D. D. Bell, Commercial chicken production manual. Chapman \& Hall, 1990.

[2] V. S. Kumar, J. Prasad, and R. Samikannu. Computational Linear Model for predicting solar energy in Botswana. 2017 International Conference on Energy, Communication, Data Analytics and Soft Computing (ICECDS). Chennai, India. 21 June 2018. p. 1-5.

[3] [Radhakrishman K., Jose N., Sanjay SG, Cherian T and Vishnu K.R. "Design and implementation of a fully automated egg incubator. International Journal of Advanced Research in Electrical, Electronics and Instrumentation Engineering (2014)

[4] M. C. Nesheim, R. E. Austic and L. E. Card, Poultry Production. Lea \& Febiger, 1979.

[5] Beaule J., Ryan M. and Salley G., Deep Cycle Batteries. Alternative Energy Store Inc., 2016. 